\section{Evolução da contagem de células T CD4+ de portadores de AIDS em contextos socialmente desiguais}

\author{
Evolution of CD4+ T-cell count among AIDS \\ patients in socially unequal contexts
}

\author{
1 Secretaria Municipal de \\ Saúde do Rio de Janeiro, Rio \\ de Janeiro, Brasil. \\ 2 Núcleo de Saúde Coletiva, \\ Universidade Federal do Rio \\ de Janeiro, Rio de Janeiro, \\ Brasil. \\ Correspondência \\ M. A. A. Patroclo \\ Secretaria Municipal de \\ Saúde do Rio de Janeiro. \\ Rua Ibiraci 140, casa 1, \\ Rio de Janeiro, $R J$ \\ 20771-030, Brasil. \\ ma.patroclo@uol.com.br
}

\begin{abstract}
This study analyzed the evolution in CD4+Tcell count in AIDS patients in the city of Rio de Janeiro, Brazil, who were on highly active antiretroviral treatment (HAART) at the Municipal Health Centers in the Maré neighborhood, located in a large slum area, and in Copacabana, located in the city's more affluent South Side. Immediately prior to HAART, the median CD4+ T-lymphocyte count was 181 cells/ $\mathrm{mm}^{3}$ in Maré and 182 cells $/ \mathrm{mm}^{3}$ in Copacabana. After 24 weeks of HAART, the median count reached 302 and $315 / \mathrm{mm} 3$ in the two health centers, respectively. Following HAART, individuals with AIDS in Maré had 2.8 times the odds of not presenting an immune response as compared to cases in Copacabana (95\%CI: 1.1-7.2). Slum residents from Maré had 3.7 the odds of not presenting an immune response as compared to slum residents from Copacabana (95\%CI: 1.2-11.5). Males from Maré had 4.4 the odds of not presenting an immune response as compared to those from Copacabana (95\%CI: 1.1-18.2). The results suggest a worse prognosis and higher case-fatality for AIDS patients from slums, independently of access to HAART.
\end{abstract}

T-Lymphocytes; Acquired Immunodeficiency Syndrome; Cell Count; Poverty Areas
Maria Aparecida de Assis Patroclo 1

Roberto de Andrade Medronho 2

\section{Introdução}

Em 1981, o mundo tomou conhecimento de uma nova doença, denominada, pelo Centers for Disease Control and Prevention (CDC; Centro de Controle e Prevenção de Doenças dos Estados Unidos), de síndrome da imunodeficiência adquirida (AIDS), e, em 1983, foi divulgada a identidade do seu agente etiológico, um retrovírus denominado vírus da imunodeficiência humana (HIV) ${ }^{1}$.

A susceptibilidade do homem ou mulher à infecção pelo HIV depende da entrada do vírus nos linfócitos T, cuja mediação é feita por moléculas receptoras da superfície da membrana celular, denominadas CD4+. A evolução natural da infecção acompanha-se no período de soroconversão por queda na contagem dos linfócitos T CD4+e aumento dos títulos virais plasmáticos. Em seguida, os títulos virais decrescem, e os níveis dos linfócitos T CD4+ elevam-se, embora geralmente não retornem aos valores máximos anteriores à infecção. Com o transcorrer do tempo, os títulos virais voltam a subir, e a contagem de células $\mathrm{T}$ CD4+ vai diminuindo acarretando o surgimento de infecções oportunistas e evolução dos casos para doença avançada e óbito num período máximo de cerca de dez anos 2,3.

Embora ainda existam controvérsias, para alguns autores, o uso da contagem de células $\mathrm{T}$ CD4+, como preditora do desfecho clínico para portadores de HIV, supera a contagem da carga viral plasmática 4,5,6. 
A progressão da AIDS para doenças oportunistas e morte tem sido demonstrada como associada, entre outros fatores, com a contagem de linfócitos T CD4+ inferior a 350células $/ \mathrm{mm}^{3}$ da mesma forma que a sobrevida longa tem sido associada ao alto quantitativo plasmático dessas células 7,8 .

Com o advento da terapia anti-retroviral, identificou-se que a resposta dos linfócitos $\mathrm{T}$ CD4+ é bifásica, com um aumento inicial que reflete a redistribuição dos linfócitos dos tecidos para o sangue, e com uma segunda fase que expressa o verdadeiro aumento no número de células. Após 4 a 8 semanas de supressão viral com esquemas anti-retrovirais altamente ativos (HAART), o aumento dos linfócitos T CD4+, em relação à contagem inicial, é, em geral, $\geq 50$ célu$\mathrm{las} / \mathrm{mm}^{3}$ 9,10,11.

Estudos mais recentes têm demonstrado existir independência entre o aumento na contagem de linfócitos T CD4+ e redução da carga viral e os tipos e classes de esquemas HAART adotados: duplo ou triplo, com inibidores de protease (IP) ou com inibidores de transcriptase reversa não análogos de nucleotídeos (ITRNN) 12 .

Após a implantação dos esquemas HAART, popularmente conhecidos como "coquetel", a AIDS passou a ser considerada como crônica e controlável, com monitoramento dos casos através da contagem de linfócitos T CD4+ (controle do grau de imunossupressão) e da carga viral (controle da multiplicação viral).

O Brasil foi um dos primeiros países no mundo a garantir acesso universal e gratuito aos medicamentos anti-retrovirais, e já, em 1991, a zidovudina (AZT) passou a ser distribuída. Em 1996, com a descoberta de novas classes de antiretrovirais mais potentes, instituiu-se a HAART; nesse mesmo ano, esses medicamentos foram incluídos no consenso brasileiro para tratamento da AIDS e distribuídos em todo o território nacional pelos serviços públicos de saúde 13 .

Apesar da descoberta dos anti-retrovirais altamente potentes, diferenciais de sobrevida para portadores de AIDS têm sido demonstrados para diferentes grupos sócio-demográficos, não sendo claro se as diferenças encontradas são reflexos de diferenças biológicas ou da diferença de acesso aos cuidados médicos, tornando-se relevante, no contexto de pauperização da epidemia, conhecer o padrão de evolução dos linfócitos $\mathrm{T}$ CD4+ em áreas socialmente desiguais em que os esquemas HAART sejam disponibilizados em serviços públicos de saúde 7 .

O objetivo deste estudo é analisar a evolução dos linfócitos T CD4+ de portadores de AIDS matriculados, no período de 2000 a 2002, em unidades públicas de saúde de áreas social- mente desiguais no Município do Rio de Janeiro, Brasil.

\section{Material e métodos}

Coorte retrospectiva de casos de AIDS matriculados nos Centros Municipais de Saúde (CMS) de Copacabana e Maré, nos anos de 2000, 2001 e 2002.

O CMS Copacabana localiza-se na 5ạ Região Administrativa da cidade do Rio de Janeiro, zona sul; e o CMS da Maré, na 30a Região Administrativa, zona norte. Ambos tinham dois médicos e uma enfermeira atuando no programa no período estudado.

Na Tabela 1, são apresentados marcadores do contexto sócio-demográfico e do contexto organizacional da assistência nas duas áreas de estudo.

Foram identificados 288 portadores de HIV/ AIDS com vinte anos ou mais, residentes em áreas adscritas ao CMS de Copacabana $(\mathrm{n}=180)$ e ao CMS da Maré $(n=108)$, matriculados no programa de DST/AIDS nos anos de 2000, 2001 e 2002 e em acompanhamento médico nesses serviços. Nessa etapa, foi realizado controle de qualidade dos endereços para confirmar o bairro e para classificar como localizado ou não em favelas.

Consideramos como desfecho o aumento de 50 ou mais células T CD4+/ $/ \mathrm{mm}^{3}$ após 24 semanas do início de HAART. Casos com aumento igual ou maior do que 50 foram classificados como tendo apresentado resposta imunológica a HAART, e casos com aumento inferior a 50 foram considerados como não tendo tido resposta imunológica.

Foram excluídos, na análise do desfecho, casos de AIDS que não faziam uso de HAART, casos com esquemas terapêuticos duplos ou monoterapia, casos que não realizaram contagem de células CD4+ antes e ou após 24 semanas de HAART, casos que tinham menos de 24 semanas de terapêutica na data de coleta de dados, e mulheres que cursaram com gravidez no período estudado.

Foram analisados, em relação ao desfecho, 38 casos de AIDS do CMS Maré e 58 casos do CMS Copacabana.

As variáveis sócio-demográficas incluídas na análise para os dois CMS foram: sexo, faixa etária, residência ou não em favela, pontos pelo Critério Rio de Janeiro/Caracas no início do cuidado e tipo de HAART.

Apenas para os portadores do CMS da Maré, foram considerados, também, anos de estudo, vínculo com a previdência social e a categoria 
Descrição do contexto sócio-demográfico e do contexto organizacional da assistência das áreas de estudo.

\section{Contexto sócio-demográfico nas áreas de estudo}

\author{
População \\ \% de população vivendo em favelas \\ Chefes de família \\ Renda
}

Escolaridade

Aglomeração domiciliar

Saneamento

Índice de Desenvolvimento Humano (IDH) 2000

Índice de educação do IDH 2000

Índice de longevidade do IDH 2000

Índice de renda do IDH 2000
$20 \%$ a mais de moradores maiores de 19 anos de idade em Copacabana

6,6\% em Copacabana e 61,4\% no Complexo da Maré

Duas vezes mais mulheres chefes de família em Copacabana

Três vezes mais chefes de família com renda até meio salário mínimo no Complexo da

Maré e 58,6 vezes mais chefes de família com renda entre 15 e 20 salários mínimos em

Copacabana

Oito vezes mais homens e 16,6 vezes mais mulheres chefes de família sem instrução no Complexo da Maré

Três vezes mais domicílios com 5 a 10 moradores no Complexo da Maré e duas vezes mais domicílios com um morador em Copacabana

66,7 vezes mais domicílios com fossa séptica; 13,9 vezes mais domicílios em que a água encanada não chegava ao interior das casas e duas vezes mais domicílios com coleta de lixo em caçamba no Complexo da Maré

Copacabana 0,956 e Complexo da Maré 0,719

Copacabana 0,990 e Complexo da Maré 0,826

Copacabana 0,879 e Complexo da Maré 0,684

Copacabana 1,0 e Complexo da Maré 0,646

Contexto organizacional da assistência nas áreas de estudos

Perfil dos portadores de HIV/AIDS matriculados nos programas

Razão Homem/Mulher

Faixa etária

Local de residência

Qualidade dos registros

Escolaridade

Vínculo com previdência social quando da matrícula no programa

Categoria de exposição

Perfil da assistência

Tempo médio entre diagnóstico sorológico e definição como caso

Tempo médio entre diagnóstico sorológico e matrícula no programa

Prevenção de doenças oportunistas

Ocorrência de doenças oportunistas

Prescrição de HAART

Busca de faltosos a consultas
1,5:1 no CMS Maré e 2,8:1 no CMS Copacabana

Na faixa de 20-39 anos, 74,0\% dos casos do CMS Maré e 69,4\% dos casos do CMS

Copacabana

9,5 vezes mais casos residentes em favela no CMS Maré

$8,3 \%$ de registros ignorados no CMS Maré

$69,4 \%$ de registros ignorados no CMS Copacabana

$19,4 \%$ de registros ignorados no CMS Maré

$100 \%$ de registros ignorados no CMS Copacabana

$5,5 \%$ de registros ignorados no CMS Maré

$55,5 \%$ de registros ignorados no CMS Copacabana

56 dias no CMS Maré e 72,5 dias no CMS Copacabana

79,5 dias no CMS Maré e 112 dias no CMS Copacabana

Profilaxia para pneumonia por Pneumocystis jirovesi (PCP) 1,5 vez mais freqüente no CMS Copacabana

Profilaxia para tuberculose três vezes mais freqüente no CMS Maré

Prevalência acumulada de tuberculose $25,9 \%$ e de neurotoxoplasmose $5,5 \%$ no CMS Maré

Prevalência acumulada de tuberculose 18,3\% e de neurotoxoplasmose 3,3\% no CMS

Copacabana

89\% dos casos de AIDS no CMS Copacabana e 74,7\% dos casos no CMS Maré

Fonte: Patroclo 21

Realizada por agentes comunitários de saúde para casos do CMS Maré 
de exposição. Essas variáveis não puderam ser analisadas para o CMS de Copacabana devido à grande proporção de registros ignorados (Tabela 1).

Os valores de carga viral não foram incluídos na análise devido ao pequeno número de casos que realizaram o exame antes e após o primeiro esquema HAART nos dois CMS.

Os dados foram analisados no programa Epi Info 2003 (Centers for Disease Control and Prevention, Atlanta, Estados Unidos), e consideradas significativas odds ratio (OR) incluídas em intervalos com 95\% de confiança (IC95\%) que não continham o valor 1 .

As limitações deste estudo referem-se ao viés de seleção decorrente da análise dos casos com acesso aos serviços e dos casos que tiveram acesso à contagem de células CD4+ antes e após o uso de HAART e casos com acesso a carga viral; além da ausência de dados referentes à escolaridade, à categoria de exposição e ao vínculo com a previdência social dos casos matriculados no CMS Copacabana.

Esta pesquisa foi aprovada, em 10 de maio de 2004, pelo Comitê de Ética em Pesquisa do Hospital Municipal Souza Aguiar, Secretaria Municipal de Saúde do Rio de Janeiro, constituído nos termos da Resolução $n^{o}$. 196/96 do Conselho Nacional de Saúde e devidamente registrado no Comitê Nacional de Ética em Pesquisas.

\section{Resultados}

Na Tabela 2, apresentamos a distribuição dos casos HIV/AIDS na primeira contagem de células T CD4+ após matrícula no programa de controle dos dois CMS selecionados. Observase que 56,6\% dos portadores de HIV no CMS da Maré e $61,8 \%$ no CMS de Copacabana tinham 350células $/ \mathrm{mm}^{3}$ ou menos, preenchendo, portanto, o critério para classificação como caso de AIDS desde o ingresso no programa. Desses, mais da metade tinha níveis de imunossupressão severa $\left(\mathrm{CD} 4+\leq 200\right.$ células $\left./ \mathrm{mm}^{3}\right)$ nos dois CMS.

$\mathrm{Na}$ Tabela 3, verifica-se que idade inferior a trinta anos foi fator de proteção para CD4+ igual ou inferior a 350células $/ \mathrm{mm}^{3}$ no CMS Maré. A utilização do Critério Rio de Janeiro/Caracas para classificação como caso de AIDS quando da matrícula no programa revelou que escore de dez pontos foi bom preditor de CD4+ $\leq 350$ células/ $\mathrm{mm}^{3}$ nos dois CMS.

Em relação as variáveis analisadas, apenas para o CMS Maré, a contagem de linfócitos T CD4+ foi maior do que 350células/mm3: 54,8\% dos portadores com oito anos ou mais de estudo;
$52,4 \%$ com vínculo com a previdência social no início do cuidado e 58,3\% dos homo/bissexuais.

Na Figura 1, estão representados valores medianos de células CD4+ imediatamente antes de HAART e 24 semanas depois. O valor mediano imediatamente antes de HAART foi de 181células $/ \mathrm{mm}^{3}$ no CMS Maré (variação 11 a 666) e de 182células $/ \mathrm{mm}^{3}$ no CMS Copacabana (variação 4 a 667). Após seis meses de HAART, o valor mediano foi de 302células $/ \mathrm{mm}^{3}$ no CMS Maré (variação 23 a 1.095) e de 315células $/ \mathrm{mm}^{3}$ no CMS Copacabana (variação 30 a 1.098). A mediana da variação foi de 119células $/ \mathrm{mm}^{3}$ no CMS Maré (variação 132 a 428) e de 131células $/ \mathrm{mm}^{3}$ no CMS Copacabana (variação 206 a 726).

Na Tabela 4, é possível constatar que, após 24 semanas de esquema HAART no CMS da Maré, $63,2 \%(24 / 38)$ dos casos tiveram aumento igual ou superior a 50 células CD4+/ $\mathrm{mm}^{3}$ e $82,8 \%$ (48/58) dos casos no CMS de Copacabana. Os casos de AIDS matriculados no CMS Maré tiveram 2,8 vezes mais chances de não apresentarem resposta imunológica do que os casos do CMS Copacabana (IC95\%: 1,09-7,23).

Nos dois CMS foram mais freqüentes a ocorrência de resposta imunológica para ambos os sexos; faixas etárias; residência em favela ou não e esquema HAART sem IP. No CMS Copacabana, o sexo masculino foi protetor para variações de CD4+ inferiores a 50células $/ \mathrm{mm}^{3}$.

Nos dois CMS, os casos que fizeram uso de HAART sem IP tiveram predominantemente variação igual ou superior a 50células $/ \mathrm{mm}^{3}$. Apenas no CMS Copacabana, os casos em uso de HAART com IP tiveram predominantemente aumento igual ou superior a 50 células $/ \mathrm{mm}^{3}$

Ainda na Tabela 4, comparando dados entre os dois CMS, detectou-se que os casos residentes em favela (18/31) do CMS Maré tiveram 3,7 vezes mais chances de não apresentarem resposta imunológica do que casos não residentes em favela (46/55) do CMS Copacabana (IC95\%: 1,21-11,49). Observou-se também que os homens (16/25) do CMS Maré tiveram 4,4 vezes mais chances de não apresentarem resposta do que os homens (39/44) do CMS Copacabana (IC95\%: 1,10-18,22).

Em relação as variáveis analisadas, apenas para o CMS Maré: escolaridade, vínculo com a previdência social e categoria de exposição não tiveram associação com resposta imunológica após uso de HAART.

Após 24 semanas de início de HAART, 69,8\% de todos os casos de AIDS, independente do CMS em que eram assistidos, alcançaram valores de CD4+ superiores a 200células $/ \mathrm{mm}^{3}$, e $44,8 \%$ tinham contagem superior a 350células $/ \mathrm{mm}^{3}$.

Os casos que alcançaram CD4+ > 200células $/ \mathrm{mm}^{3}$, após seis meses de HAART, tiveram 5,3 
Distribuição dos portadores de HIV/AIDS, segundo classes de células T CD4+ na primeira contagem após a matrícula no programa.

\begin{tabular}{lcccc}
\hline $\begin{array}{l}\text { Classes de CD4+ na primeira } \\
\text { contagem (células/mm3) }\end{array}$ & \multicolumn{2}{c}{ CMS Maré (N = 76) } & \multicolumn{2}{c}{ CMS Copacabana (N = 102) } \\
& Freqüência & $\%$ & Freqüência \\
\hline 200 & 27 & 35,5 & 43 & 42,2 \\
$>200$ e $\leq 350$ & 16 & 21,1 & 20 & 18,6 \\
$>350$ e $\leq 500$ & 11 & 14,5 & 21 & 17,6 \\
$>500$ & 22 & 28,9 & 102 & 20,6 \\
Total & 76 & 100,0 & 100,0 & 102 \\
\hline
\end{tabular}

CMS: Centro Municipal de Saúde.

Tabela 3

Primeira contagem de células T CD4+, após matrícula no programa, segundo unidades de saúde.

\begin{tabular}{|c|c|c|c|c|c|c|c|c|}
\hline \multirow[t]{3}{*}{ Variáveis } & \multicolumn{4}{|c|}{ CMS Maré $(N=76)$} & \multicolumn{4}{|c|}{ CMS Copacabana $(N=102)$} \\
\hline & $\leq 350$ & $>350$ & OR & IC95\% & $\leq 350$ & $>350$ & OR & IC95\% \\
\hline & células $/ \mathrm{mm}^{3}$ & células $/ \mathrm{mm}^{3}$ & & & células $/ \mathrm{mm}^{3}$ & células $/ \mathrm{mm}^{3}$ & & \\
\hline \multicolumn{9}{|l|}{ Sexo } \\
\hline Masculino & 29 & 23 & & & 49 & 26 & & \\
\hline Feminino & 14 & 10 & 0,90 & $0,34-2,40$ & 14 & 13 & 1,75 & $0,71-4,27$ \\
\hline \multicolumn{9}{|c|}{ Faixa etária (anos) } \\
\hline $20-29$ & 6 & 13 & & & 20 & 15 & & \\
\hline 30 e mais & 37 & 20 & 0,25 & $0,08-0,76$ & 42 & 23 & 0,73 & $0,32-1,69$ \\
\hline \multicolumn{9}{|c|}{ Residência em favela } \\
\hline Não & 7 & 6 & & & 57 & 36 & & \\
\hline Sim & 36 & 27 & 0,87 & $0,26-2,90$ & 6 & 3 & 0,79 & $1,19-3,37$ \\
\hline \multicolumn{9}{|c|}{ Pontos do Critério Rio de Janeiro/ } \\
\hline \multicolumn{9}{|c|}{ Caracas no início do cuidado } \\
\hline$<10$ & 25 & 29 & & & 45 & 36 & & \\
\hline 10 & 17 & 5 & 0,25 & $0,07-0,88$ & 17 & 3 & 0,22 & $0,05-0,89$ \\
\hline
\end{tabular}

CMS: Centro Municipal de Saúde.

vezes mais chances de apresentarem resposta imunológica do que aqueles que persistiram com CD4+ $\leq$ 200células $/ \mathrm{mm}^{3}$ (IC95\%: 1,78-16,24).

Níveis de CD4+ $\leq 350$ células $/ \mathrm{mm}^{3}$ foram mantidos no CMS Maré para 24 casos após HAART; desses, 13 tiveram variação inferior a 50 células, e 11 tiveram variação igual ou superior. No CMS Copacabana, 29 casos mantiveram CD4 $\leq 350$ células $/ \mathrm{mm}^{3}$; desses, 6 tiveram variação inferior a cinqüenta células, e 23 tiveram variação igual ou superior. Os portadores de AIDS do CMS da Maré que permaneceram com CD4+em níveis de imunossupressão (CD4+ $\leq 350$ células $/ \mathrm{mm}^{3}$ ) , após HAART, tiveram 4,5 vezes mais chances de não apresentarem resposta imunológica do que os do CMS de Copacabana (IC95\%: 1,17-18,27).
Em relação à manutenção de níveis de imunossupressão severa, no CMS Maré, 12 portadores de AIDS mantiveram CD4+ $\leq 200$ células/ $\mathrm{mm}^{3}$, após HAART; desses, 9 tiveram variação inferior a 50 células, e 3 tiveram variação igual ou superior. No CMS Copacabana, 17 casos permaneceram com níveis de imunossupressão severa; desses, 5 apresentaram variação inferior a 50 células, e 12 apresentaram variação igual ou superior. Os portadores de AIDS do CMS Maré que se mantiveram em níveis de imunossupressão severa, após HAART, tiveram 7,2 vezes mais chances de não apresentarem resposta imunológica do que os portadores do CMS Copacabana (IC95\%: 1,35-38,33). 
Figura 1

Mediana da contagem de células CD4+ antes e após anti-retrovirais altamente ativos (HAART).

Centro Municipal de Saúde (CMS) Maré e Copacabana, Rio de Janeiro, Brasil.

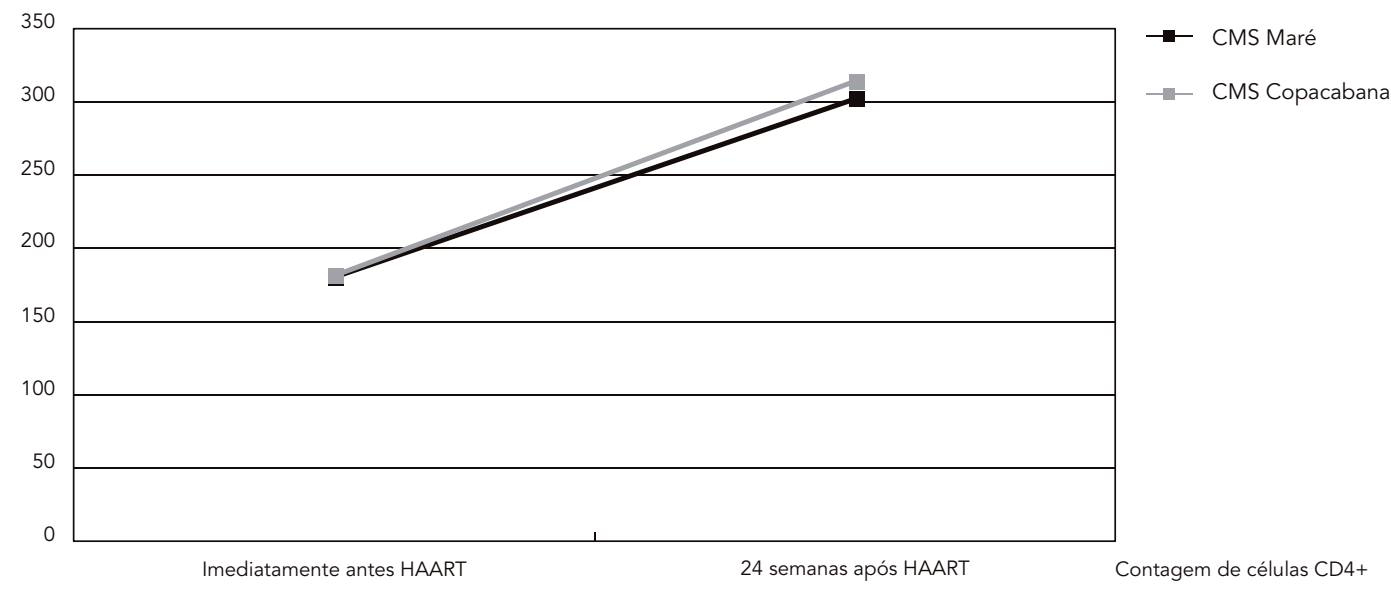

Tabela 4

Variação de células CD4+, após 24 semanas do primeiro esquema anti-retroviral altamente ativo (HAART), segundo unidades de saúde.

\begin{tabular}{|c|c|c|c|c|c|c|c|c|}
\hline \multirow[t]{3}{*}{ Variáveis } & \multicolumn{4}{|c|}{ CMS Maré (N = 38) } & \multicolumn{4}{|c|}{ CMS Copacabana $(N=58)$} \\
\hline & $<50$ & $\geq \mathbf{5 0}$ & OR & IC95\% & $<50$ & $\geq \mathbf{5 0}$ & OR & IC95\% \\
\hline & células $/ \mathrm{mm}^{3}$ & células $/ \mathrm{mm}^{3}$ & & & células $/ \mathrm{mm}^{3}$ & células $/ \mathrm{mm}^{3}$ & & \\
\hline \multicolumn{9}{|l|}{ Sexo } \\
\hline Masculino & 9 & 16 & & & 5 & 39 & & \\
\hline Feminino & 5 & 8 & 0,90 & $0,23-3,59$ & 5 & 9 & 0,23 & $0,05-0,97$ \\
\hline \multicolumn{9}{|l|}{ Faixa etária (anos) } \\
\hline $20-29$ & 3 & 4 & & & 2 & 18 & & \\
\hline 30 e mais & 11 & 20 & 1,36 & $0,26-7,23$ & 8 & 28 & 0,39 & $0,07-2,04$ \\
\hline \multicolumn{9}{|c|}{ Residência em favela } \\
\hline Não & 1 & 6 & & & 9 & 46 & & \\
\hline Sim & 13 & 18 & 0,23 & $0,02-2,15$ & 1 & 2 & 0,39 & $0,03-4,79$ \\
\hline \multicolumn{9}{|l|}{ Tipo de HAART } \\
\hline Tríplice sem IP & 11 & 23 & & & 7 & 36 & & \\
\hline Tríplice com IP & 3 & 1 & 0,16 & $0,01-2,10$ & 3 & 12 & 0,78 & $0,14-4,55$ \\
\hline
\end{tabular}

CMS: Centro Municipal de Saúde; IP: inibidor de protease. 


\section{Discussão}

$\mathrm{O}$ alto percentual de portadores de HIV com contagem de células T CD4+ $\leq 350$ células $/ \mathrm{mm}^{3}$, no início do cuidado, nos dois CMS estudados, expressou o acesso tardio aos serviços públicos de saúde no Município do Rio de Janeiro. Esses achados podem estar contribuindo para os coeficientes de mortalidade por AIDS, pois sobrevida maior tem sido relatada como associada significativamente com alta contagem de $\mathrm{CD} 4+$ para aqueles que iniciam cuidados médicos precocemente ${ }^{8}$.

Contagem de células T CD4+ $\leq 350$ células/ $\mathrm{mm}^{3}$ foi predominante para o sexo masculino nos dois CMS estudados, e o mesmo foi observado para os heterossexuais no CMS Maré. Contagem acima de 350células $/ \mathrm{mm}^{3}$ no início do cuidado ocorreu principalmente para aqueles com oito anos ou mais de estudos, homo e bissexuais, no CMS Maré. Nesse CMS, a idade $<30$ anos foi fator de proteção para baixa contagem de CD4+. Esses dados se aproximam dos resultados de estudos nos quais idade mais velha, sexo masculino e exposição heterossexual tiveram associação significativa com menor contagem de CD4+ 14,15.

Estudos têm demonstrado que o tempo de sobrevida para casos de AIDS aumentou substancialmente para adultos brasileiros após HAART, e que, no Município do Rio de Janeiro, $82 \%$ dos casos matriculados em serviço público responderam aos esquemas anti-retrovirais após 24 semanas. Neste estudo, para os casos residentes em área onde predominam favelas, foram encontradas 2,8 vezes mais chances de ausência de resposta imunológica após HAART do que para residentes em área de elites. Nossos achados revelam que, entre populações desiguais, podem ocorrer diferenças significativas em relação à resposta imunológica a HAART que podem contribuir para diferenciais de sobrevida e de morbidade. Utilizando, no Município do Rio de Janeiro, estratificações que distinguiam populações residindo em favelas de populações segundo status socioeconômico foram identificadas que as piores condições de saúde estavam em setores com alta concentração de favelas, evidenciando que os diferenciais de saúde seguem o mesmo padrão da segregação geográfica 13,16,17.
Os residentes em favelas tiveram 3,7 vezes mais chances de não apresentarem resposta imunológica do que os residentes em áreas de elite (IC95\%: 1,21-11,49). Observou-se também que homens assistidos no CMS Maré, localizado em complexo de favelas, tiveram 4,4 mais chances de não apresentarem resposta imunológica do que homens assistidos no CMS Copacabana, localizado em área de elites (IC95\%: 1,1018,22). Discordâncias foram encontradas ao se analisar estudos que buscavam identificar associação entre pobreza, renda e sobrevida com AIDS, não estando esclarecido se, nesses estudos, os resultados foram devidos à alta mortalidade para AIDS antes de HAART, ao acesso similar ou desigual a cuidados médicos e ao uso de HAART $18,19,20$.

Os resultados encontrados neste estudo sugerem um pior prognóstico e provavelmente maior letalidade para portadores de AIDS residentes em favelas, independente do acesso a HAART.

\section{Conclusões}

A análise da evolução da contagem de linfócitos T CD4+ para portadores de HIV/AIDS, vivendo em dois contextos socialmente desiguais no Município do Rio de Janeiro, evidenciou que o benefício resultante do uso de HAART após 24 semanas foi comum, com aumentos medianos superiores a 100células $/ \mathrm{mm}^{3}$ para os dois tipos de população.

Ausência de resposta imunológica após seis meses de HAART foi significativamente maior para homens e para casos residentes em área de favelas quando comparados aos homens e aos casos não residentes em favela de área de elites.

Sendo a pauperização uma das características da epidemia da AIDS desde a última década do século XX e universal o uso de HAART no Brasil, considera-se relevante a inclusão de indicadores de desigualdade social que distingam favela de nível socioeconômico nos estudos de evolução da AIDS em nosso país, permitindo, dessa forma, que se identifiquem áreas específicas em que o controle da epidemia requer esforços diferenciados e de caráter intersetorial. 


\section{Resumo}

Este estudo analisou a evolução da contagem de células T CD4+ em portadores de AIDS do Município do Rio de Janeiro, submetidos a esquemas anti-retrovirais altamente ativos (HAART), no Centro Municipal de Saúde (CMS) da Maré, localizado em complexo de favelas e no de Copacabana, localizado em área de elites. Imediatamente, antes de HAART, a mediana de linfócitos $T$ CD4+ foi 181 células $/ \mathrm{mm}^{3}$ na Maré e 182células $/ \mathrm{mm}^{3}$ em Copacabana. Após 24 semanas de HAART, a mediana alcançou 302 e 315 células $/ \mathrm{mm}^{3}$ nos dois CMS, respectivamente. Após HAART, os portadores de AIDS da Maré tiveram 2,8 vezes mais chances de não apresentarem resposta imunológica do que casos de Copacabana (IC95\%: 1,1-7,2). Residentes em favelas da Maré tiveram 3,7 mais chances de não apresentarem resposta imunológica do que não residentes em favelas de Copacabana (IC95\%: 1,2-11,5). Homens da Maré tiveram 4,4 mais chances de não apresentarem resposta imunológica do que os de Copacabana (IC95\%: 1,1-18,2). Resultados sugerem pior prognóstico e maior letalidade para portadores de AIDS residentes em favelas, independente do acesso a HAART.

Linfócitos T; Síndrome de Imunodeficiência Adquirida; Contagem de Células; Áreas de Pobreza

\section{Colaboradores}

M. A. A. Patroclo contribuiu com o desenho do estudo, revisão bibliográfica, coleta de dados, análise e redação do artigo. R. A. Medronho orientou e participou da análise e revisão de todas as etapas do estudo e do artigo.

\section{Referências}

1. Garret L. A próxima peste: as novas doenças de um mundo em desequilíbrio. Rio de Janeiro: Editora Nova Fronteira; 1994.

2. Biolo A, Seligman BGS, Sprinz E, Rowlands-Jones SL. In: Spriz E, Finkelsztejn A, et al. Rotinas em HIV e AIDS. Porto Alegre: Editora Artes Médicas Sul; 1999. p. 26-9

3. Pokhrath H. HIV-1 transmission and acute HIV-1 infection. Br Med Bull 2001; 58:109-27.

4. Piketty C, Weiss L, Thomas F, Mohamed AS, Belec L, Kazatchkine MD. Long-term clinical outcome of human immunodeficiency virus-infected patients with discordant immunologic and virologic responses to a protease inhibitor-containing regimen. J Infect Dis 2001; 183:1328-35.

5. Yerly S, Kaiser L, Perneger TV, Cone RW, Opravil $\mathrm{M}$, Chave JP, et al. Time of initiation of antiretroviral therapy: impact on HIV-1 viraemia. AIDS 2000, 14:243-49.

6. Mellors JW, Munoz A, Giorgi J, Margolick JB, Tassoni CJ, Gupta P, et al. Plasma viral load and CD+ lymphocytes as prognostic markers of HIV-1 infection. Ann Intern Med 1996; 126:946-54.
7. Chaisson RE, Keruly JC, Moore RD. Race, sex drug use, and progression of human immunodeficiency virus disease. N Engl J Med 1995; 333:751-6.

8. Hogg RS, Strathdee SAA, Craib KJ, Oshanghnessy MV, Montner JS, Schechter MT. Lower socioeconomic status and shorter survival following HIV infection. Lancet 1994; 344:1120-4.

9. Autran B, Carcelain G, Li TS, Blanc C, Mathez D, Tubiana R, et al. Positive effects of combined antiretroviral therapy on CD4+ cell homeostasis and function in advanced HIV disease. Science 1997; 277:112-6.

10. Bucy RP, Hockett RD, Derdeyn CA, Saag K, Squires $\mathrm{M}$, Sillers RT, et al. Initial increase in blood CD4 (+) lymphocytes after HIV antiretroviral therapy reflects redistribution from lymphoid tissues. J Clin Invest 1999; 103:1391-8.

11. Le Moing V, Thiebaut R, Chene G, Leport C, CailletonV, Michelet C, at al. Predictors of long - term increase CD4 (+) cell counts in human immunodeficiency virus infected patients receiving a protease inhibitor containing antiretroviral regimen. J Infect Dis 2002; 185:471-80. 
12. Highly active antiretroviral therapy including protease inhibitors does not confer a unique CD4 cell benefit. The AVANTI and INCAS Study Groups. AIDS 2000; 14:1383-8

13. Marins JR, Jamal LF, Chen SY, Barros MB, Hudes ES, Barbosa AA, et al. Dramatic improvement in survival among adult Brazilian AIDS patients. AIDS 2003; 17:1675-82.

14. Pezzotti P, Phillips AN, Dorrucci M, Lepri AC, Galai N, Vlahov D, et al. Category of exposure to HIV and age in the progression to AIDS: longitudinal study of 1199 people with know dates of seroconversion. BMJ 1996; 313:583-6.

15. Swati B, Gilbert RL, Brady AR, Linvingstone SJ, Evans BG. CD4 cell counts in adults with newly diagnosed HIV infection: results of surveillance in England and Wales, 1990-1998. AIDS 2000; 14:853-61.

16. Hofer CB, Schechter M, Harrison LH. Effectiveness of antiretroviral therapy among patients who attend public HIV clinics in Rio de Janeiro, Brazil. J Acquir Immune Defic Syndr 2004; 36:967-71.
17. Szwarcwald CL, Bastos FI, Barcellos C, Pina MF, Esteves MAP. Health conditions and residential concentration of poverty: a study in Rio de Janeiro, Brazil. J Epidemiol Community Health 2000; 54:530-6.

18. Katz MH, Hsu L, Lingo M, Woelffer G, Schwarcz SK. Impact of socioeconomic status on survival with AIDS. Am J Epidemiol 1999; 148:282-91.

19. Kopp C, Lang S, von Overbeck J. Socio-demographic and life-style factors in a Swiss study of HIV non-progression. Schweiz Med Wochenschr 1999; 129:1397-404.

20. McFarland W, Chen S, Hsu L, Schwarcz S, Katz M. Low socioeconomic is associated with a higher rate of died the era of highly active antiretroviral therapy. J Acquir Immune Defic Syndr 2003; 33:96-103.

21. Patroclo MAA. Perfil de portadores de HIV/AIDS em áreas socialmente desiguais [Dissertação de Mestrado]. Rio de Janeiro: Núcleo de Estudos de Saúde Coletiva; Universidade Federal do Rio de Janeiro; 2005.

Recebido em 02/Jun/2006

Versão final reapresentada em 22/Dez/2006

Aprovado em 16/Jan/2007 